Archivum, LXX (I), 2020, pp. 193-227

\title{
¿Estamos solos? Divulgación científica y representación literaria de la vida extraterrestre en magazines chilenos $(1900-1915)^{*}$
}

\author{
Verónica RAmírez ErrázUriz \\ Universidad Adolfo Ibáñez/Fondecyt, Chile \\ vramirez@uai.cl
}

Recibido: 03/09/2019

Aceptado: 29/11/2019

\section{RESUMEN:}

A fines de la década de 1870 el astrónomo italiano Giovanni Schiaparelli reportó el descubrimiento de supuestos canales en el planeta Marte. A partir de entonces se sostuvo una controversia entre aquellos que aprobaban y desaprobaban dicha teoría. Durante los primeros años del siglo xx esta discusión científica se intensificó y permeó sustancialmente las páginas de periódicos, especialmente de magazines, puesto que, por una parte, la controversia estaba supeditada a pruebas ópticas y este tipo de publicaciones gozaba de moderna tecnología material y fotográfica, y por otra, porque estas revistas tenían características idóneas para que un problema científico traspasara los lindes de la ciencia y se relacionara con otros saberes y temáticas. Este trabajo estudia la cober-

* Este trabajo fue desarrollado en el marco del proyecto FONDECYT Postdoctoral n. ${ }^{\circ}$ 3180131, titulado Astronomía y literatura en Chile: diálogo y discusión en el espacio público (1880-1930), actualmente en ejecución. 
tura de la controversia sobre los canales en Marte, cuyo interés social se centró en la posibilidad de la vida extraterrestre. La propuesta implica analizar los modos en que se divulgó y representó localmente esta teoría astronómica de alcance global, a través de la revisión de los principales magazines chilenos de principios del siglo $\mathrm{xx}$, tales como Sucesos, Zig-Zag, Corre-Vuela y Pacífico Magazine.

PALABRAS CLAVE: astronomía, literatura, divulgación científica, prensa, Chile, siglo $\mathrm{xx}$.

Are we alone? Scientific dissemination and literary representation of extraterrestrial life in Chilean magazines (1900-1915)

\begin{abstract}
:
At the end of the 1870s, the Italian astronomer Giovanni Schiaparelli reported the discovery of supposed channels on the planet Mars. From then on, there was a controversy between those who agreed and disagreed with this theory. During the early years of the twentieth century this scientific discussion intensified and permeated the pages of magazines (especially illustrated and cultural magazines) for two main reasons. First, because the controversy was subject to optical testing, and secondly, because magazines were able to include visual devices such as photographs thanks to advances in the printing industry. Our work studies the coverage in the Chilean magazines of this controversy about the channels on Mars that resulted in the question of whether or not there was life on the red planet (the channels were supposedly artificial rivers that would have been built by some intelligent living being). The proposal involves analyzing the ways in which these astronomical theories that circulated globally were disseminated and represented locally by reviewing some of the main Chilean magazines of the early twentieth century, such as Sucesos, Zig-Zag, Corre-Vuela and Pacífico Magazine.
\end{abstract}

KEYWORDS: Astronomy, Literature, Scientific dissemination, Press, Chile, 19th Century.

\title{
1. Introducción
}

Comprender la ciencia como un producto acabado y elaborado por un grupo de expertos a puertas cerradas en un espacio delimitado es una idea que ha sido ampliamente superada. En las últimas décadas los trabajos seminales de Steven Shapin y Simon 
Schaffer (1985), así como de Bruno Latour (1987), han puesto en duda - desde la perspectiva de la historia de la ciencia - la idea de que existe un lado interno y externo de la ciencia. Desde esta nueva visión, el conocimiento es entendido no como un producto, sino como un proceso en el cual interactúan distintos agentes sociales, por lo que la generación y transmisión de conocimientos deberían comprenderse como actividades vinculadas "con la construcción de espacios y prácticas de sociabilidad" (Sanhueza Cerda, 2018, 15). Algunos autores han postulado, además, que la ciencia es un proceso comunicativo per se, de tal modo que producir conocimiento científico no puede separarse de comunicar este (Secord, 2004, 654). Desde esta perspectiva, la ciencia es definida como una práctica que dialoga con otros saberes y disciplinas, a través de la cual se sostiene un permanente intercambio de discursos, contenidos, metodologías, etc., supeditado a múltiples intereses. Nuestro trabajo se enfoca en este diálogo, específicamente en la interacción entre el saber astronómico y el literario dentro del espacio público chileno en los primeros años del siglo $x x$.

El surgimiento de la esfera pública burguesa, como ha planteado Habermas (1999), fue facilitado por el desarrollo de una variedad de centros de sociabilidad en los pueblos y ciudades modernas, donde se podían establecer discusiones en ciertos planos de igualdad de condiciones entre intereses privados y públicos. El desarrollo de la prensa moderna fue un elemento clave para constituir dicho espacio, por lo que los soportes periodísticos del periodo, cada vez más amplios y diversificados, "nos permiten inferir o suponer algunas de las grandes tendencias o rasgos que definen los escenarios públicos nacionales" (Ossandón y Santa Cruz, 2005, 250). Dentro de la vastedad de géneros periodísticos, las revistas ilustradas misceláneas o magazines, que comenzaron a circular en Chile los primeros años del siglo $\mathrm{xx}$, tuvieron características particulares, tales como su propósito comercial y el soporte tecnológico con el que gozaron, lo que les permitió incorporar material iconográfico (fotografías e ilustra- 
ciones) como uno de sus aspectos centrales (Alvarado Cornejo, 2011, 82-83). Ambos atributos son relevantes para los objetivos de nuestro análisis, puesto que, por una parte, el modelo de negocio de estos proyectos los condujo a utilizar el conocimiento científico como un producto comercial (Nieto-Galan, 2011, 66), y por otra, su soporte fotográfico permitió potenciar considerablemente la transmisión del conocimiento astronómico.

Durante los primeros quince años del siglo xx en Chile, la industria editorial y periodística sufrió una importante modernización relacionada también al aumento de la tasa de alfabetismo en la población y a la profesionalización de los periodistas y escritores (Ossandón y Santa Cruz, 2005, 118). Los magazines más fructíferos en ese período fueron los gestados por los fundadores de editorial Zig-Zag, Agustín Edwards Mac-Clure y Gustavo Helfmann, cuyas publicaciones conforman el corpus de fuentes de nuestro trabajo. Las revistas de esta empresa "se configuraron como la respuesta burgués-empresarial frente a los múltiples discursos culturales, literarios, artísticos, sociales, políticos, informativos, entre otros, que en 1905 configuraban públicos lectores específicos" (Alvarado Cornejo, 2011, 85). En estos medios la función de informar acerca de fenómenos celestes convivió con la sobrerrepresentación y espectacularización ${ }^{1}$ de estos últimos, revelando un titubeo esencial de estas revistas entre supeditar la información a la entretención y viceversa. Esta doble función de los magazines es la que creemos que posibilitó que ciertas teorías científicas promovieran la escritura de textos de divulgación que, sin limitarse a transmitir el conocimiento, se desplazaron hacia el terreno literario.

A lo anterior se debe agregar que a fines del siglo xIX y principios del xx no existían límites claros entre la pura ficción literaria, la ciencia ficción y la divulgación científica, favoreciendo que la escritura de los divulgadores de la ciencia se mantuviera entre la novela, el texto académico y la divulgación (Nieto-Galan, 2010, 
74-75). Esto último se relaciona directamente con el concepto de ciencia en aquel entonces, ya que lo que se entendía por 'científico' era más amplio y heterodoxo que en la actualidad. Durante el siglo xix y las primeras décadas del xx 'lo científico' es atribuido tanto a lo que concierne a las llamadas ciencias materialistas como a las ciencias ocultas, existiendo entre ellas una confusa línea divisoria (Quereilhac, 2016, 9-10).

Una de las teorías científicas que circuló ampliamente en los magazines fue la de la existencia de canales o ríos artificiales en el planeta Marte, que contenía de manera implícita la posibilidad de vida inteligente fuera de la Tierra. Esta teoría provocó la instalación de una controversia científica a nivel global que alcanzó gran atención entre 1900 y 1915, y fue protagonizada por astrónomos connotados que la aprobaban o rechazaban. La discusión estaba supeditada al avance tecnológico de los instrumentos de observación, así como al desarrollo de la astrofísica y del análisis espectroscópico, que permitió conocer los elementos que componen los astros. Si bien el origen de esta desavenencia científica se remonta a años anteriores al periodo estudiado, ${ }^{2}$ fue durante la primera década del siglo xx que alcanzó su clímax, culminando en 1909, cuando se confirmó la inexistencia de los famosos canales mediante comprobación óptica. La evidencia, no obstante, no desanimó a los crédulos, ya que a partir de entonces los telescopios se fijaron hacia Venus y Júpiter, donde se esperaba hallar lo que no se pudo encontrar en Marte. La cobertura en la prensa sobre esta temática perdió fuerzas abruptamente tras el estallido de la Primera Guerra Mundial (Crowe, 1986, 539).

En esta controversia astronómica la riña entre la imaginación y el avance tecnológico fue clave, puesto que a falta de instrumentos que pudieran comprobar o refutar lo que realmente acontecía en Marte, se volvió imparable la imaginación de los científicos. Tal como dice Sheehan (1988), en la astronomía el paso siguiente

2 El astrónomo italiano Giovanni Schiaparelli publicó la observación de canales en Marte en 1877 y su propuesta se vinculó desde sus inicios con la interrogante sobre la posible vida extraterrestre. 
a la observación es la interpretación, y entre ambas etapas metodológicas existe un espacio para especular e imaginar (Sheehan, 1988, 99). Este vacío fue amplio en el contexto estudiado, puesto que todavía no existía la fotografía tomada desde astronaves. ${ }^{3}$ Los magazines y su materialidad iconográfica fueron dispositivos muy apropiados para la alimentación y transmisión de esta controversia, puesto que la disputa se balanceaba entre las pruebas visuales tomadas por los astrónomos que estos mismos hacían circular y los textos e ilustraciones que representaban la curiosa e increíble posibilidad de la vida inteligente en Marte, siendo ambos recursos (textos e imágenes) reproducibles por estas revistas. Esta situación promovió un ambiente propicio para que la astronomía y la literatura dialogaran con intensidad.

Considerando la problemática recién expuesta, los siguientes apartados pretenden responder: ¿Cómo representaron los magazines a nivel local la teoría sobre Marte y la vida extraterrestre? ¿Cómo interactuaron en ese contexto la escritura científica y literaria? ¿Qué relevancia tuvo el magazine para la explicación científica y la representación literaria de esta teoría?

La perspectiva de la historia de la ciencia mencionada al inicio de esta introducción, el concepto del espacio público y la relevancia de la prensa sostenidos por Habermas, la comprensión de la ciencia como un producto de consumo, así como la inexistencia de límites claros entre la divulgación científica y la ficción en este periodo (Nieto-Galan, 2011), conforman parte del entramado teórico que nos permitirá contextualizar el desarrollo de estas preguntas. Desde allí se profundizará en el problema de la naturaleza literario-científica de las fuentes estudiadas y de las particularidades de la representación literaria de un fenómeno científico como el descrito. Para esto último, discutiremos con el trabajo de Greg Myers (1990), que visualiza las características literarias de la escritura científica, lo que será complementado con las ideas de Hayden White (1973), para quien todo es un relato de ficción. Es

3 Esta recién se inauguró con el sobrevuelo del Sputnik 1, primer satélite artificial lanzado al espacio en 1957. 
importante aclarar que el acento de nuestro análisis se concentrará en identificar los elementos contextuales que intensificaron el diálogo entre ambos discursos - el científico y el literario-, por lo que no pretendemos ahondar en la inviable pregunta sobre qué es lo que define específicamente la literaturidad de cada texto.

\section{La discusión científica sobre la vida extraterrestre en el pe- riodo finisecular}

Para comprender el modo en que dialoga la astronomía y la literatura en el proceso de circulación del conocimiento sobre la vida extraterrestre, es imprescindible enterarnos del desarrollo y los hitos de la controversia sobre los canales de Marte.

La controversia científica sobre las características de la superficie del planeta Marte tuvo su inicio en 1877 cuando el astrónomo italiano Giovanni Schiaparelli (1835-1910) publicó su observación del planeta. El científico veía líneas rectas en varios puntos, lo que lo llevó a interpretar y defender durante toda su carrera que esas líneas debían ser canales o ríos hechos artificialmente, debido a la prolijidad y exactitud de estas. Schiaparelli era un observador con cierto prestigio mundial, por lo que su interpretación no pasó desapercibida. Desde entonces estableció una nueva manera de abordar el estudio de Marte y de generar conocimiento sobre este planeta, impulsando una intensa controversia que se mantuvo hasta el año 1909, pero que solo se desmanteló plenamente en 1965 cuando la astronave sin tripulación Mariner 4 pudo sobrevolar la superficie marciana y realizar sus primeras fotografías cercanas (Sheehan, 1988, 85-86). Fue el poder de la influencia y la sugestión la que alimentó la convicción de múltiples astrónomos seguidores de Schiaparelli ${ }^{4}$ y, por contraparte, fue el escepticismo y la convicción de que aún era muy limitada la tecnología, lo que mantuvo firmes a los detractores.

Entre los astrónomos más reconocidos por su defensa a los canales de Marte, se encontraban el ya nombrado Schiaparelli, el 
científico estadounidense Percival Lowell (1855-1916) y el francés Camille Flammarion (1842-1925). Los dos últimos denominaron al primero como el "Columbus of Mars" (Sheehan, 1988, 110) y creyeron fehacientemente tanto en las observaciones del italiano, como en las líneas rectas que les mostraban sus propios telescopios ubicados en Arizona (Estados Unidos) y Juvisy (Francia), respectivamente. El protagonismo de Lowell se consolidó desde 1894, dos años después de que Schiaparelli concluyese sus estudios del planeta. Flammarion, por su parte, recibió constante atención gracias a su prolífica popularización de las observaciones de Marte. La difusión que hicieron estos tres científicos fue de tal magnitud que la temática se hizo familiar en diversos rincones del mundo. ${ }^{5}$

Las empresas periodísticas vieron en este fenómeno una oportunidad de negocio, como también la percibieron en otras temáticas científicas (Nieto-Galan, 2011, 66), por lo que se dedicaron a sobreexponer los distintos avances de la disputa y, muchas veces, a sobreinterpretar las afirmaciones de los astrónomos. Un aspecto interesante, en ese sentido, fue la visión romántica que instaló Schiaparelli desde su primera observación de Marte en 1877, quien para recordar los accidentes geográficos del planeta nominó estos de manera poética. Algunos nombres fueron "el lago del Sol" y "la Bahía de la Aurora", de tal modo que un ejercicio que al comienzo pudo tener fines prácticos para el científico italiano (recordarle ciertos puntos específicos del planeta), más tarde, gracias a la circulación de sus observaciones, terminaría atribuyéndole un carácter psicológico y mítico, reportándole una visión nostálgica, contraria a la del Paraíso (Sheehan, 1988, 89). Fue a partir de entonces que el planeta rojo comenzó a verse en analogía con la Tierra, convirtiéndose en una representación ampliamente utilizada por artistas y escritores literarios.

Los supuestos ríos artificiales del planeta propuestos por Schiaparelli decantaron más tarde en su teoría de la germinación

5 Lowell y Flammarion publicaron libros al respecto durante la primera década del siglo xx: Mars and its Canal (1906), el norteamericano, y La Planète Mars et ses conditions d'habitabilité (1909), el francés. 
o de posible vida vegetal y animal sustentada en vastos puntos azulados de Marte. Estas ideas fueron contenidas hacia fines del siglo xIx y principios del xx en la teoría de Lowell sobre la conformación de mares momentáneos gracias al derretimiento de zonas polares del planeta, relacionado a la composición de la atmósfera de Marte, lo que mantenía a los canales artificiales como las vías a través de las cuales los supuestos marcianos dirigirían los deshielos a las zonas ecuatoriales. Estas ideas fueron complementadas, finalmente, con las especulaciones de Flammarion sobre la existencia de vida más avanzada que la nuestra, amparadas en que Marte era más viejo que la Tierra (Flammarion, 1909, 592).

Los detractores de estas propuestas, por el contrario, fueron tomando cada vez más fuerza en la medida en que se desarrollaban instrumentos de observación más potentes. Así, los astrónomos Edward Maunder (inglés), William Campbell (estadounidense) y Eugène Antoniadi (francés-griego) fueron siendo cada vez más escuchados, hasta prácticamente hacer desaparecer la teoría de los canales en 1909. Antoniadi entró en la arena de discusión a fines de del siglo XIX, cuando apoyándose en el comentario de Vincenzo Cerulli de 1896, ${ }^{6}$ promovió su oposición a los seguidores de Schiaparelli durante la primera década del siglo $\mathrm{xx}$, acusando que a estos los envolvía una ilusión de los ojos (Crowe, 1986, 519). En la oposición de Marte ${ }^{7}$ de 1909, Antoniadi, así como el astrónomo español Comas i Solà, obtuvieron pruebas contundentes que provocaron, junto a la muerte de Schiaparelli en 1910 y la de Lowell en 1916, que la leyenda de los canales comenzara a apagarse (Crowe, 1986, 524).

El esfuerzo profesional y económico dedicado a este fenómeno durante tres décadas fue enorme. Distintos observatorios enfocaron sus lentes hacia el planeta, se invirtieron amplios recur-

6 Cerulli afirmó que si se observaba la Luna con un instrumento menos potente, también se veían líneas.

7 La oposición de un planeta sucede cuando la Tierra se encuentra al centro entre el Sol y el planeta en un mismo meridiano. Cuando eso ocurre, dicho planeta es visible toda esa noche y ocupa su posición más cercana a la Tierra. 
sos para mejorar los instrumentos y se financiaron expediciones hacia lugares terrestres con mejores condiciones para la observación. Percival Lowell, por ejemplo, organizó para la oposición de Marte de 1907 una expedición a Chile dirigida por David Todd, donde se pudieron obtener trece mil nuevas placas del planeta. Todas las fotografías capturadas en este proyecto exhibían las famosas líneas de Marte, lo que alimentó la persistencia de los que defendían los ríos artificiales por algunos años más (Crowe, 1986, 528).

Las imágenes capturadas, generalmente complementadas con dibujos y textos para proporcionar mayor nitidez (Crowe, 1986, 528), circularon en la prensa, en especial, en soportes que incluían fotografías, como los magazines. Para dar cuenta de la dimensión que alcanzaba la difusión de estas representaciones mencionamos el ejemplo de Flammarion, quien todo lo que publicó tan solo el año 1904 acerca del planeta Marte, circuló por la prensa de Argentina, México, Venezuela, Francia, Rusia, Hungría, Suecia, Chile, entre otros países, pasando a ser tema de conversación, no solo entre científicos, sino también entre políticos, artistas (Crowe, 1986, 524) y la población en general. Esta capacidad de popularizar la astronomía de parte de Flammarion lo llevó a posicionarse como el gran difusor de esta ciencia durante el periodo, pero también a ser catalogado como un especulador 'sensacionalista' por parte de sus detractores.

Tras las pruebas obtenidas en 1909 todavía sobrevivieron defensores de los canales de Marte, algunos incluso se mantuvieron firmes hasta la década de $1960,{ }^{8}$ cuando se obtuvieron fotografías lo suficientemente cercanas. La evidencia lleva a concluir, sin embargo, que alrededor de 1912 los astrónomos profesionales habían llegado al consenso de que la existencia de canales en Marte había sido desacreditada (Crowe, 1986, 539). No correría la misma suerte la teoría sobre la posibilidad de vida en otros planetas, la que como es sabido sigue latente hasta nuestros días. 
Dejar de lado a Marte no se tradujo en clausurar la problemática de la posible vida extraterrestre, sino todo lo contrario, abrió el campo hacia la observación de otros planetas, tales como Venus y Júpiter, así como al interés en la astronomía estelar.

\section{Los canales de Marte: su divulgación y representación lite- raria en Chile}

El 1 de septiembre de 1898 apareció en La Revista de Chile un pequeño texto titulado "Los canales de Marte y de la Luna". En este se incluyó una nota extraída del Boletín de la Sociedad Astronómica de Francia firmada por el astrónomo italiano Vincenzo Cerulli, donde se desautorizaba la teoría de los canales de Marte. El astrónomo planteaba que, si al observar la Luna con un lente de menor potencia se veían líneas, era muy probable que las que se veían en Marte a través del telescopio respondieran al mismo efecto óptico:

En vista de esto podemos sostener que los canales de Marte no son, sino simples alineaciones de manchas parecidas a las que el telescopio nos permite ver en la Luna. Por último, podemos sostener que una vez que los progresos de la óptica nos permitan sustituir los telescopios actuales por otros de mayor poder, los canales de Marte perderán también su figura de líneas que los hace hoy tan misteriosos e interesantes. (La Revista de Chile, 1898, 255)

Tal como decíamos en el apartado anterior, Cerulli había publicado esta hipótesis en 1896, lo que da cuenta de la velocidad con la que circulaba este tipo de conocimientos hacia zonas alejadas de Europa, tales como Sudamérica, a través de soportes no especializados como los magazines.

Si bien La Revista de Chile es anterior al periodo estudiado y no gozó plenamente del proceso de modernización de la materialidad de las revistas, ${ }^{9}$ la hemos incluido como fuente porque

9 La Revista de Chile fue fundada en 1898 por Gustavo Holley. Dejó de circular en 1901. 
nos permite constatar que a fines del siglo xIx ya existía cierta atención local hacia esta controversia global. Pero este interés cobraría mayor fuerza durante los primeros años del siglo $\mathrm{xx}$, cuando comenzaron a circular los magazines, cuya característica principal fue la introducción de un soporte material moderno, ofreciendo mejor calidad en sus impresiones. La cobertura de la problemática sobre los canales de Marte y la posibilidad de vida inteligente en este planeta fue constante en las páginas de Sucesos, Zig-Zag, Corre-Vuela y Pacífico Magazine, ${ }^{10}$ donde además de adjuntar respaldo fotográfico para abrazar o rechazar esta teoría, se produjo un intenso diálogo entre propósitos científicos y fines literarios. Nuestro trabajo contempla la revisión de estas cuatro revistas de la editorial chilena Zig-Zag, porque tuvieron un contundente y extenso alcance en el país. Corre y vuela (19081927) se dirigió hacia un público más popular, Pacífico Magazine (1913-1921) a un grupo más selecto, culto y exigente, mientras que Sucesos (1902-1932) y revista Zig-Zag (1905-1964) fueron más transversales, enfocadas en los intereses de la clase media. Como puede comprobarse, la editorial contaba con una variada gama de lectores y consumidores de distintos niveles socioculturales. ${ }^{11}$

El diálogo entre los propósitos divulgativos y los fines literarios en estas revistas respondió a un cierto contexto, puesto que a fines del siglo xIx y principios del xx eran sumamente difusos los límites entre la pura ficción literaria, la ciencia ficción y la divulgación científica, por lo que las obras literarias a menudo

10 Estos fueron cuatro de los magazines más importantes que publicaron en Chile los fundadores de editorial Zig-Zag durante el periodo. Sucesos fue creada por los hermanos Gustavo y Alberto Helfmann en Valparaíso el año 1902, y circuló hasta 1934 al amparo de Editorial Zig-Zag. La revista homónima (Zig-Zag) nació en 1905, su gestor fue Agustín Edwards Mac-Clure y circuló hasta 1964. Corre-Vuela publicó un número semanal entre 1908 y 1927. Pacífico Magazine lo hizo entre 1913 y 1921.

11 Otros magazines de esta empresa fueron El Peneca (1908-1960), Familia (19101928 y 1935-1940) y Selecta (1909-1912). La primera revista estaba dirigida a una audiencia infantil, la segunda, al público femenino, y la tercera fue destinada al fomento exclusivo del arte y la literatura. En este trabajo no consideraremos estas tres revistas, ya que nos enfocaremos en aquellas que mantuvieron como esencia la multiplicidad temática y que apuntaron hacia una audiencia más heterogénea. 
inspiraban la escritura de textos de divulgación (como fue el caso de los textos de Louis Figuier), o los científicos creaban obras de ficción para reforzar su programa de divulgación (como Camille Flammarion). Esto favoreció que la difusión de la ciencia se mantuviera entre los datos empíricos y el relato novelesco (Nieto-Galan, 2011, 274-275). En ese sentido, la ficción no necesariamente se presentaba en formato de novela o cuento, sino que también había textos de divulgación atravesados profundamente por ella. Las controversias científicas, sobre todo las que involucraban temáticas que encendían la imaginación de la población, como la posible vida extraterrestre, fueron instancias favorables para intensificar este diálogo entre la escritura científica y literaria.

$\mathrm{Si}$ bien en este trabajo no pretendemos analizar obras de ciencia ficción propiamente, nuestras fuentes dialogan de algún modo con dicho género, por lo que consideramos necesario al menos esbozar una definición de este. Comprenderemos por ciencia ficción "writing a story that preserves something like the effects of a disturbing dream, while grounding those effects in plots that not depend on supernatural events" (Alkon, 2002, 5). Entendido así, este género no puede echar mano a lo sobrenatural para ir más allá de lo humanamente posible, pero sí puede recurrir potencialmente a ello mediante la fusión de la imaginación y la experimentación científica. Las obras de ciencia ficción se nutren del contenido científico, por lo que a su propósito conscientemente literario se suma inconscientemente el rol divulgativo. En las novelas de Julio Verne, por ejemplo, se proporcionan en clave literaria elementos sólidos de cultura científica (Nieto-Galan, 2011, 73). Lo interesante es que esta relación también se puede dar de manera inversa, es decir, un texto que parece tener un propósito consciente de hacer divulgación científica, también puede involucrarse con funciones literarias, como ocurre en las publicaciones de los magazines que difunden acerca del planeta rojo y de sus posibles condiciones para la vida. Así en momentos en que la controversia científica sobre los canales de Marte se encontraba en uno de sus puntos más álgidos, aparecieron textos 
sobre esta materia que fluctuaban entre lo científico y lo literario. El 21 de julio de 1907 revista Zig-Zag publicó un texto titulado "El llamado de otro mundo", aludiendo a que los telegrafistas de la estación Marconi recibieron repetidas veces durante el año 1901 una señal de tres golpes cuyo emisor nunca se pudo descifrar. El enigmático llamado se asoció popularmente con los tres puntos luminosos o tres manchas blancas que algunos observadores de Marte habían reportado en su superficie ese mismo año. Respecto a ello se lee lo siguiente: "Tres golpes significan S. en el alfabeto Morse, pero en la práctica telegráfica significan también: ¿Está usted allí? [...] ¡Tal vez Marte envía las tres señales anunciando la apertura de una cortina que ha estado corrida desde el principio de los tiempos!" (Zig-Zag, 1907). Una vez que el redactor instala este enigma y da paso a una posibilidad virtual, comienza a entregar información científica incrustando imágenes sobre las particularidades del planeta rojo:

Marte posee una atmósfera cuya composición, estudiada por el espectroscopio, [...] es parecida a la de nuestra Tierra. [...]. Su diámetro es la mitad del de la Tierra y, por consiguiente, su volumen es solo la séptima parte. [...]. El planeta emplea un poco más de 686 días en recorrer su órbita alrededor del Sol. [...]. Las manchas verdes son los mares y las otras distintivamente rojas, son los continentes que, al contrario de nuestra tierra, son mucho más extensos que los mares. [...]. Las aguas de Marte son repartidas con amplitud, confinadas a los mares interiores, que se reúnen después de largos canales [...]. Los observadores de Marte se han dedicado a atribuir esas líneas a canales cavados por los habitantes para satisfacer las necesidades de su civilización. (Zig-Zag, 1907)

El escritor, como se puede ver, vuelve al plano de las posibilidades y, para potenciar esto último, representa cómo habrían de ser los supuestos habitantes de Marte, citando para ello una obra de Flammarion literaria y no 'divulgativa' específicamente su novela Urania (1896), lo que explicita la asociación del propó- 
sito divulgativo y literario del texto. Myers postula que la diferencia crucial entre un artículo científico y un texto literario no radica en el contenido de estos, sino en la forma, sobre todo en el tipo de retórica que emplea (Myers, 1990, 4). Sin embargo, en el texto de Zig-Zag, así como en los próximos ejemplos que expondremos, es prácticamente imposible diferenciar una retórica de orden literario de otra de orden científico, puesto que ambas están totalmente fundidas. En ese sentido, las palabras de Hayden White respecto a la supuesta naturaleza científica del texto histórico, parecieran ser más precisas para nuestro análisis. White afirmaba que "en cualquier campo de estudio todavía no reducido (o elevado) a la situación de auténtica ciencia, el pensamiento permanece cautivo del modo lingüístico en que intenta captar la silueta de los objetos que habitan el campo de su percepción" (White, 1973,11). De esta manera, un texto que divulga conocimiento científico en un magazine podría identificarse como uno no elevado plenamente a la situación de ciencia auténtica, puesto que no se trata de un escrito que pretende transmitir información y datos científicos de manera técnica, por lo que tendría una alta predisposición a permanecer cautivo del modo lingüístico en que capta y representa lo que percibe. Viéndolo de esta manera, no debería sorprendernos la doble naturaleza científica y artística de estos escritos, ya que sería algo común y propio a su naturaleza. Sin embargo, el problema de aplicar las ideas de Hayden White de este modo, es que no estaríamos considerando el contexto en que se publicaron estos artículos en los magazines estudiados. En ese periodo la categoría de "auténtica ciencia" planteada por White no tiene plena cabida. Como no existía una idea clara y universal de qué se entendía por ciencia y de qué era lo 'auténticamente científico', el problema se trasladaba también a la definición de qué era un texto científico y qué no. Como aún no se formaban delimitaciones establecidas en ese sentido, para un lector no era sencillo identificar si lo que leía era un texto científico, divulgativo o literario, como tampoco le resultaba fácil la diferenciación entre lo que hacía un cientí- 
fico propiamente tal, un divulgador de la ciencia y un escritor. Flammarion, entre otras personalidades de la época, contribuía a dicha confusión, en cuanto que se destacaba en los tres roles, es decir, como astrónomo, como divulgador de la ciencia y como escritor literario. Insistimos, después de esta reflexión, que el interés de nuestro trabajo no radica en identificar qué es lo literario y qué es lo científico de las fuentes estudiadas, sino identificar los elementos externos, contextuales, que propiciaron una fuerte intensificación de la fusión ya existente entre la escritura científica y literaria en la época.

Textos semejantes al anterior fueron publicados constantemente en revista Zig-Zag entre 1907 y 1909. Así, por ejemplo, el 10 de mayo de 1908 apareció uno titulado "Cómo es la vida en Marte”. En su introducción se lee: “¿Existe la vida en Marte? He aquí una pregunta que contestan afirmativamente todos los que han estudiado tan interesante materia" (Zig-Zag, 1908). El autor del texto que firma con una $X$, desconoce o elude a propósito la controversia que tiene ampliamente agitados a los astrónomos, ya que asume que "todos" quienes analizan este planeta con cierta dedicación estarían de acuerdo en que existe vida en él. Sus referencias, en consecuencia, parecen limitarse solo a aquellos astrónomos que defendían los canales de Marte y, partiendo desde esa base, se preguntó: “¿Cómo es esa vida?" (Zig-Zag, 1908). Para responder esto último el escritor fusionó referencias a observaciones realmente desarrolladas y defendidas por expertos con elucubraciones que traspasan estas teorías. En algunos de sus párrafos leemos que la estatura de los marcianos "es dos veces la del ser humano. Estará favorecido por alas de una especie de membranas semejantes a las del murciélago y su piel será probablemente cabelluda" (Zig-Zag, 1908). Esta representación de los habitantes de Marte pudo inspirarse en obras literarias, pero también en datos ya demostrados científicamente sobre ciertas características de Marte, tales como su baja temperatura (de allí el cuerpo cabelludo) y la menor fuerza de gravedad que ejerce el planeta sobre los cuerpos (de allí las alas). Por lo 
que el texto utiliza esos contenidos científicos y transita hacia la ficción, es decir, narra especulando ciertos acontecimientos posibles cuya verosimilitud se fundamenta narrativamente en el campo de las ciencias físicas y naturales, que es una de las propiedades de la ciencia ficción. Así puede leerse en la parte final de este texto: "Las circunstancias de haber producido el hombre de Marte obras tan perfectas como los canales nos autorizan para creer que está dotado de brazos y manos y además de un órgano especial de aprehensión: una trompa o una hilera de tentáculos" (Zig-Zag, 1908).

Si revisamos otros magazines del periodo observamos una relación entre el tono científico y literario semejante al recién descrito. Revista Sucesos, por ejemplo, publicó en 1908 un texto que expone la topografía y los ríos de Marte a través de ilustraciones (Imagen 1) proporcionadas por un experto cuyo nombre no se explicita.

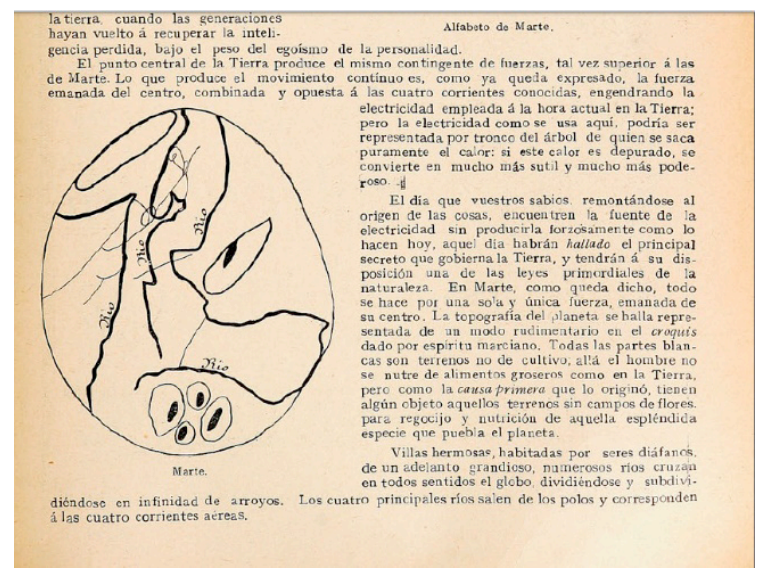

Imagen 1

Al mismo tiempo, el texto afirma que lo que se describe corresponde a la comunicación de un espíritu marciano que habría aclarado a los terrícolas algunas interrogantes sobre su planeta. 
A través del juego ficcional se declara que entre estas verdades se encuentra que: "en Marte todo se hace por una sola y única fuerza, emanada de su centro" (Sucesos, 1908) o que "las líneas [...] no son mares: estos no existen en Marte", sino que "cuatro fuerzas dirigen el planeta, produciendo cuatro corrientes" (Sucesos, 1908).

Es cierto que entre la escritura científica y literaria existen diversos puntos en común de manera permanente (Nieto-Galan, 2011, 73-80). El científico, por ejemplo, emplea el lenguaje metafórico para referirse a fenómenos que se escapan de la comprensión humana, de hecho, "la lógica del descubrimiento es la metaforización" (Meyer, 1980, 81). La ciencia, por lo demás, tiene una dimensión lingüística, está formada por enunciados (Marcos, 2010, 11), por lo que "el empleo del término 'poética' en relación con la creatividad científica no es nuevo" (Marcos, 2010, 325). Pero en este trabajo queremos remarcar que existen ciertas instancias en que la fusión entre la escritura científica y la literaria se intensifican, como fue el caso de la controversia de los canales y la hipótesis de la vida inteligente que derivaba de estos durante la primera década del siglo xx. Lorena Valderrama (2016) ha explicado que terremotos, cometas y eclipses ofrecen atractivos espectáculos para científicos y audiencias más amplias, convirtiendo estos fenómenos en experiencias sublimes y elevando la imaginación hasta el punto de lo no imaginable, en el cual las palabras pueden llegar a ser impotentes para representar lo vivido (Valderrama, 2016, 169174), por lo que recurrir a la ficción en estos casos podría ser una herramienta de expresión. Con los canales de Marte, sin embargo, ocurre algo distinto, puesto que se trataba de una teoría basada en observaciones que no podían ser captadas a simple vista humana. En consecuencia, el atractivo que despertó provino casi netamente de la cobertura que le dio la prensa al fenómeno y de las representaciones textuales y visuales que estos medios transmitieron y produjeron. 


\section{Sobrerrepresentación y sensacionalismo científico en maga- zines: la vida extraterrestre después de 1909}

Después de haber dedicado múltiples páginas a la teoría de los canales de Marte, los magazines chilenos dejaron de pronunciarse sobre Marte. El olvido del planeta rojo por los editores de estas revistas seguramente se debió a las observaciones generadas en la oposición de Marte en 1909 por Antoniadi y Comas i Solà, quienes contando con lentes más poderosos pudieron respaldar científicamente la inexistencia de los canales.

No obstante, las revistas no desatendieron la idea sobre posible vida extraterrestre, sino simplemente desplazaron el foco hacia otros puntos del universo. Algunos títulos de textos publicados desde 1909 en adelante fueron: "Los habitantes de Júpiter. Un mundo de gigantes y vendaval continuo" (1909), "El sol habitable" (1911) y "Paisajes celestes" (1915) en la revista Corre-Vuela; también “¿Vegetación en los planetas?” (1914) en la revista Sucesos; y "El universo ulterior" (1915) y “¿Están habitados los planetas?" (1915) en la revista Zig-Zag. Esta proliferación de textos coincide con el comportamiento de otros dispositivos, tales como el libro, cuyo registro de publicaciones solo del año 1916 arroja un total de 140 títulos sobre vida extraterrestre (Crowe, 1986, 547).

La discusión sobre la vida extraterrestre desde el punto de vista científico siguió viva sobre todo porque persistía una fuerte tendencia a dar excesiva verosimilitud a la observación (Crowe, 1986, 550), y el acto de 'ver' está totalmente atravesado de aspectos subjetivos. Tal como señala William Sheehan $(1988,99)$, la percepción involucra más que la mera recepción de datos, puesto que su ejercicio implica clasificar la imagen en función de algunas características que permitan que su identidad sea captada. La observación astronómica, como podemos inferir, se enfrenta constantemente a objetos desconocidos, por lo que en este proceso la expectación juega un rol crucial, de modo que lo que uno espera ver genera la ilusión de estar viéndolo (Sheehan, 1988, 129). Las visiones particulares, además, al provenir de observa- 
dores connotados, como fue Schiaparelli, por ejemplo, provocan ilusiones colectivas. Asimismo, la susceptibilidad entre los mismos científicos a querer ver lo que otros y ellos mismos esperan ver, sumado a un estado anímico popular favorable para ello, provocó que afloraran "traficantes de sensaciones", como los llama Sheehan (1988), dispuestos a generar sensacionalismo sobre teorías sustentadas en la observación.

A esto último debe agregarse que la discusión sobre la pluralidad de mundos involucraba necesariamente a otras disciplinas, más allá de la astronomía, tales como la meteorología, biología, química, óptica, etc., e incluso saliendo del campo científico propiamente tal, la filosofía y la religión, entre otras más (Crowe, 1986, 559), por lo que al ser una temática transversal, todos creían tener el derecho a pronunciarse públicamente desde las más variadas perspectivas, generándose cruces de discursos complejos.

Finalmente, hay un tercer elemento que debería considerarse como alimento para la circulación de teorías sobre vida extraterrestre en aquellos años. Nos referimos a la necesidad de legitimación de los expertos, quienes para ello recurrían (y siguen haciéndolo) a la aprobación de las audiencias. La prensa, en ese sentido, es un medio que permite a los científicos consolidar su experticia ante la sociedad, y el fuerte interés social en un fenómeno o teoría específica - en este caso, astronómica- es una oportunidad para quienes quieran consolidarse como autoridades científicas en una disciplina. Los científicos, por lo tanto, aprovechando el escenario favorable, dirigieron su interés de investigación y produjeron un mayor número de textos sobre la posible vida extraterrestre.

En estas tres dimensiones recién expuestas sale a la luz la perspectiva histórica que inspira este trabajo, es decir, la urgencia de revisar la manera en que circulaba el conocimiento científico desde una visión que incluye a grupos y sujetos que desde la mirada tradicional no se les ha considerado como agentes activos de generación de conocimiento científico, como serían en este caso los editores, colaboradores y lectores de magazines de 
distribución masiva. Tal como han postulado Jürgen Renn (2015) y Agustí Nieto-Galan (2011 y 2016), los públicos de la ciencia deben ser comprendidos como agentes activos del proceso de generación del conocimiento científico. Los magazines chilenos siguen demostrando desde 1909 en adelante, que la ficción tenía un rol relevante para transmitir y representar un problema de bases científicas.

La revista Corre-Vuela en 1909 ofreció atención al planeta Júpiter, señalando que: “Después de que tanto se ha hablado de Marte y de los habitantes que se le supone, es natural que tratemos de saber si en otros planetas, en Júpiter, por ejemplo, hay también seres más o menos semejantes nuestros, y qué aspecto tienen" (Corre-Vuela, 1909). El texto menciona que un astrónomo norteamericano ya se está ocupando de este asunto, basándose en hechos comprobados por la ciencia y llegando a una serie de conclusiones curiosas, referencia a la que añade el dato verificado acerca de la alta velocidad con la que rota Júpiter sobre su eje (el cálculo es de 500 kilómetros por hora en su ecuador). A partir de dicha base científicamente probada, el escrito conjetura acerca de los jovianos (habitantes de Júpiter), afirmando que "para poder resistir el ímpetu de aquel fuerte viento, tendrán cuando menos quince o veinte metros de estatura" (Corre-Vuela, 1909). Luego agrega: "para quienes el coger y echarse a cuestas una casa de dos pisos sería tarea relativamente sencilla, poco más o menos como para un mozo de cuerda de los nuestros cargarse un baúl" (Corre-Vuela, 1909). Estas descripciones, fundamentadas primero en datos científicos, como la velocidad de rotación de Júpiter, y en la necesidad de producir imágenes comprensibles para los lectores legos, van cobrando a lo largo del texto características que escapan a dichos conocimientos y propósitos, y penetran en el campo de la ficción, como ya veíamos en los apartados anteriores. Así leemos: "No hay nunca guerras [en Júpiter], y ello es natural, pues los buenos jovianos tendrán bastante quehacer con construir y reparar abrigos y refugiarse lo bastante fuertes para resistir al tremendo huracán ecuatorial" (Corre-Vuela, 1909). O bien que su 
"comercio exigirá barcos de construcción especial, acaso submarinos, porque los mares de Júpiter azotados por el consabido ciclón han de ser los más turbulentos" (Corre-Vuela, 1909). De este modo, los conocimientos sobre tal planeta fluyen hacia imágenes y representaciones curiosas y atractivas, llegando a atribuir a sus habitantes voces con la potencia de un león - para comunicarse por sobre el torbellino-, o una piel más gruesa que un elefante - para no ser cortada por el viento- (Corre-Vuela, 1909).

El texto titulado “¿Vegetación en los planetas?", publicado en revista Sucesos en agosto de 1914, responde al mismo esquema. Este inicia con un dato científico comprobado: "En vista de que el examen espectroscópico hace deducir la presencia de clorofila en los planetas, vuélvese a discutir la cuestión de la vida vegetal en esos mundos misteriosos" (Sucesos, 1914). La prueba fotográfica aparece como protagonista en esta publicación, que incrusta en una parte central de la página reproducciones de las placas obtenidas por el astrónomo Percival Lowell desde su observatorio en Arizona. "En esos espectrogramas hay ciertas líneas oscuras que no pertenecen, como las demás, a metales existentes en la Tierra. Experimentos repetidos han demostrado que la clorofila, la materia verde colorante de las plantas, da un espectro que coincide precisamente con esas líneas" (Sucesos, 1909). Este tipo de observaciones enfocadas en un objeto que no es familiar intentan ser reconocidas mediante aproximaciones a categorías intermedias, proceso en el que se abre el umbral hacia la imaginación (Sheehan, 1988, 99). El texto concluye con una invitación a soñar sobre una rica vida vegetal fuera de nuestro planeta. El discurso es amplificado rotundamente por medio de las imágenes incorporadas. Por un lado, se añade la fotografía espectroscópica de Lowell, acentuando la base científica de lo que se comunica y, por otro, se adjunta una ilustración de un paisaje con vegetación exuberante acompañada de un pie de texto que versa así: “Una maravillosa vegetación parece existir en Neptuno" (Imagen 2), enlazando el respaldo experimental a la ilusión, lo que otorga cierta credibilidad a un juego ficcional. 


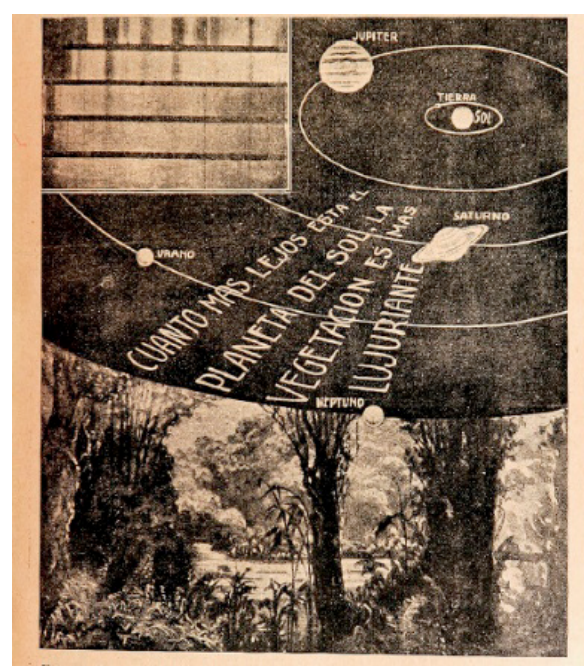

Imagen 2

No creemos que el entrar en este juego provoque que el texto pierda plenamente su carácter científico, sobre todo porque la vegetación en Neptuno puede entenderse como una gran metáfora y la escritura científica siempre se ha servido de este recurso (Marcos, 2010, 349). Lo destacable es que el texto se mantiene justamente entre las dos funciones, la científica y la literaria, desafiando la definición genérica y acercándose hacia los terrenos de la ciencia ficción. La descripción de este último género definida por Isaac Asimov (1957) es aplicable a este texto divulgativo sobre Neptuno y a varios otros de las páginas de los magazines, es decir, estos se ocupan de alguna $u$ otra manera, desde una perspectiva literaria, del impacto del avance científico en los seres humanos.

En la revista Zig-Zag también encontramos publicaciones semejantes. El año 1915 es prolífico en textos como este. En enero apareció uno titulado: “Están habitados los planetas?”. El redactor (que no firma con su nombre) se pregunta: “¿Cuáles serían nuestras impresiones si pudiéramos trasladarnos a uno de esos 
planetas y estudiar sobre el terreno los aspectos que allí presentan la vida y la naturaleza?" (Zig-Zag, 1915a). A lo que responde: "Pero lo que en el hecho nos está vedado, la ciencia imaginariamente nos lo permite" (Zig-Zag, 1915a). Luego de nombrar algunos datos que la ciencia ha podido afirmar con seguridad sobre los planetas, tales como sus dimensiones, temperaturas, tiempo de rotación, etc., imagina partiendo desde dichos datos. Su representación de Venus, por ejemplo, se constituye por aspectos sumamente detallados que en su conjunto podrían dialogar con el infierno dantesco:

Venus es lo que la paleontología llama un mundo de la época secundaria. Un mundo de pesadillas, un astro de monstruos, donde reina una atmósfera asfixiante, saturada de agua caliente, y cuyo aspecto general es un vasto pantano donde flotan vegetales podridos y que emanan gases mefíticos [...]. Allí se esconden horribles reptiles, y se ven repugnantes y colosales alimañas desconocidas de nosotros [...]. Los insectos son monstruos [...]. Por doquier se sienten aullidos siniestros y silbidos atemorizantes [...]. No se ven en aquel paraje flores armoniosas ni pájaros cantores, sino flores repugnantes y pájaros enormes que lanzan graznidos fúnebres. (ZigZag, 1915a)

Al igual que Zig-Zag, la revista Corre-Vuela publicó ese mismo año (1915) la traducción de un texto de Lucien Rudaux, ${ }^{12}$ astrónomo y artista francés, fundador y director del observatorio de Donville, miembro de la Sociedad Astronómica de Francia y creador de famosas pinturas sobre motivos espaciales. Nuevamente nos percatamos de que a partir de observaciones reiteradas veces discutidas y confirmadas sobre los planetas, se elucubró sobre la manera de representar dichas visiones. Su texto titulado "Paisajes celestes" revelaba no solo el interés de este científico por la representación pictórica y la perspectiva visual, 
sino también por la contextualización de ese interés supeditado a una discusión científica de relevancia en la época, "el conocimiento de otros mundos" (Corre-Vuela, 1915), como él explica. Si bien el texto al principio transcurre atado a datos comprobados, en su desarrollo despliega representaciones interesantes y ficticias de cómo habrían de ser los paisajes de otros mundos. Así, desde una afirmación como la siguiente, "El carácter esencial del mundo lunar es la falta de aire en cantidad sensible. En estas condiciones no hay lejanías ni luz difusa. Todas las oposiciones, así los primeros como los últimos planos, ofrecen la misma tosquedad" (Corre-Vuela, 1915); se permite avanzar hacia otras como:

Un viajero que se parara en Mercurio, el planeta más próximo del Sol $[. .$.$] vería, gracias a esta proximidad, imperando en un$ paisaje montañoso y a través de un velo atmosférico muy débil, sin duda, un Sol colosal que derramara torrentes de fuego. [...] Desde Venus, más alejada del Sol, pero más próxima todavía que la Tierra [...], lo haría aparecer como una estrella inmensa, cuyo deslumbramiento encendería el espeso gas aéreo. Desde Marte, por el contrario, más alejado que nosotros, un Sol la mitad más pequeño iluminaría el suelo, plano en su generalidad, y seco. (Corre-Vuela, 1915)

La preocupación de este astrónomo por la variedad de percepciones de la luz desde los distintos planetas seguramente se originó en su vocación artística. De tal manera que la pregunta por el conocimiento de los otros mundos se muestra profundamente anclada en este texto a la posibilidad de sumar a nuestro espectro perceptivo terrestre un sinnúmero de enfoques, planos, intensidades, etc., posicionados desde múltiples puntos del universo. Su interés por describir cómo se vería la Tierra desde otros ángulos revela el propósito anterior e impulsa el deslizamiento del discurso hacia el campo de la ficción. Por lo que su interés en la discusión científica sobre la pluralidad de 
mundos se enmarcaba en voltear la perspectiva sobre la que se observa el universo, y en abrirse a la posibilidad de que sea la Tierra la visualizada y descrita desde esos múltiples mundos. Así declara en su texto: “Las noches más claras de Venus serían las apropiadas para contemplar la Tierra que irradia magníficamente en el cielo" (Corre-Vuela, 1915). Desde Marte, en cambio, "se ve la Tierra como una magnífica estrella de la tarde o de la mañana $[. .$.$] . Y a medida que nos alejamos del Sol, sobre los$ enormes planetas distantes, esta impresión de debilitada luz y de melancolía, se hace más grande" (Corre-Vuela, 1915). Estas impresiones abren el camino hacia la problemática planteada por Asimov (1953) de cómo ha de impactar el adelanto científico a los seres humanos.

Concluiremos este apartado refiriéndonos a un texto de Flammarion que publicó Zig-Zag en abril de 1915. Lo particular de este último, titulado "El universo ulterior", es que su dinámica es inversa a la que hemos venido describiendo en los escritos anteriores. En este caso el astrónomo inicia sus ideas con una escritura cuya función es total y evidentemente literaria y, en la medida en que avanza el texto, va incorporando la función divulgativa. Las primeras líneas se expresan así:

En un sistema solar perteneciente a la constelación de Andrómeda, existía un planeta cuyo volumen era un millón de veces mayor que el de nuestra tierra, y que llevaba en su superficie una humanidad muy avanzada. Los ojos de sus habitantes estaban dispuestos de una manera muy distinta de los nuestros, y con ellos percibían radiaciones que permanecen ocultas para nosotros. (ZigZag, 1915b)

La apertura es equivalente a la de un cuento o novela, donde su intención parece ser la de simplemente narrar una historia evidentemente virtual. Pero tras contar un largo relato sobre los supuestos habitantes de este planeta de otra galaxia, el autor avanza hacia la explicación de la evolución del planeta Tierra y 
del Universo, dando cuenta que la historia ficticia previa habría servido para comprender esto último. Si bien el ejercicio es inverso en comparación con los textos anteriores, la relación entre escritura científica y literaria se presenta con igual intensidad.

\section{Las controversias científicas en los magazines: ¿una instancia para informar o para entretener a las audiencias?}

Las controversias científicas son, como señalamos anteriormente, un escenario propicio para la legitimación de expertos antes las audiencias. El caso de los canales de Marte, como pudimos ver, se utilizó de puente para que ciertos astrónomos se dieran a conocer dentro de la comunidad y adquirieran renombre y autoridad en la materia. En ese sentido, tanto los que apoyaron o refutaron la teoría de los canales de Marte y la evidencia de la vida extraterrestre, se beneficiaron. Las controversias científicas, no obstante, producen reacciones y efectos mucho más complejos que los ya descritos. Así, por ejemplo, entre científicos que están de acuerdo en una posición surgen otras disputas derivadas del punto en común, como fue el caso de la pública discusión que protagonizaron Antoniadi y Comas i Solà para reclamar el carácter prioritario de sus investigaciones individuales que refutaban la existencia de los canales de Marte en 1909 (Ruiz-Castell, 2011). Las controversias científicas, además, deben comprenderse como fenómenos sociales, puesto que evidentemente se ven influenciadas por convenciones sociales y valores culturales (Ruiz-Castell, 2011, 531).

Los magazines estudiados, como se ha demostrado, se afanaron en transmitir la controversia de los canales de Marte de la manera más amplia posible, añadiendo respaldos (fotografías, mapas, etc.) que habrían de darle la razón a uno u otro experto. Pero estas revistas en sí mismas también se jugaban una cierta legitimación en este tipo de contextos. Sus editores se desvivían por demostrar la autenticidad de los documentos que publicaban y por acreditar que se citaban o reproducían fuentes legítimas. Lo interesante es que este afán de informar de manera fidedig- 
na, rozaba con el otro propósito básico de este tipo de proyectos periodísticos, esto es, la entretención. Los magazines, como ya decíamos en la introducción, operaron como negocios, por lo que su supervivencia estaba directamente ligada al avisaje y a la captación de suscriptores, lo que a su vez dependía de la capacidad de hacer convivir con éxito ambas funciones: la de informar y entretener.

Las fuentes que hemos analizado revelan el esfuerzo de los editores por enfrentarse debidamente a esta encrucijada. La inclusión de la función literaria en el texto divulgativo y viceversa, es decir, la inclusión de la función divulgativa en el texto literario, creemos que responden a esta problemática. Los magazines revelan, además, que cada cierta cantidad de ediciones se presentaba una visión que mitigaba la ficción sobre la teoría de vida extraterrestre, que había procurado mantener entretenidas a las audiencias, para dar paso al propósito paralelo de informar responsablemente. Debemos tener en cuenta que estas empresas editoriales, como la dirigida por Edwards Mac-Clure en Chile, no podían descuidar la satisfacción tanto de aquellos que buscaban informarse para profundizar sobre algún hallazgo o acontecimiento científico como de los que solo querían entretenerse en función de la temática.

Esa dinámica de interrumpir la ficción cada cierta cantidad de números, se patenta con algunos textos. Uno de ellos fue publicado en septiembre de 1911 en la sección "Variedades" de Corre-Vuela y se refiere en tono sarcástico a la teoría de Young (astrónomo norteamericano), quien postulaba que el Sol era habitable. El texto señala que

Mr. Young, contra cuanto se ha pretendido demostrar sobre el astro rey de nuestro sistema, sostiene la teoría de que el Sol es un planeta habitable y lo que llama la ciencia luz y calor solar, son transformaciones de poderosas corrientes eléctricas que están en constante movimiento cruzando el espacio entre los astros. (Corre-Vuela, 1911) 
Frente a esta nueva propuesta científica sobre la vida extraterrestre, la revista opta por no dar espacio a la imaginación y corta drásticamente tal posibilidad, cerrando el texto de la siguiente manera: "Falta que el mencionado sabio nos demuestre cómo se producen los cambios de estaciones, los eclipses y el día y la noche, según esa su nueva teoría" (Corre-Vuela, 1911).

Por otra parte, en 1907 Sucesos incluye un texto firmado por Moreaux, director del Observatorio de Burgos, que rechazaba la especulación y ficcionalización que había generado la controversia sobre los canales de Marte:

El planeta Marte ha servido de pretexto en estos últimos años a obras novelescas y utópicas de no escaso mérito, pero que son puros trabajos de imaginación y fantasía. En realidad, los seres inteligentes y los animales que han poblado esa tierra del cielo, ¿habrán podido resistir los rigores de ese clima polar? Sería poco científico afirmarlo y, dígase lo que se quiera, nada prueba la existencia de una raza inteligente en Marte. (Sucesos, 1907)

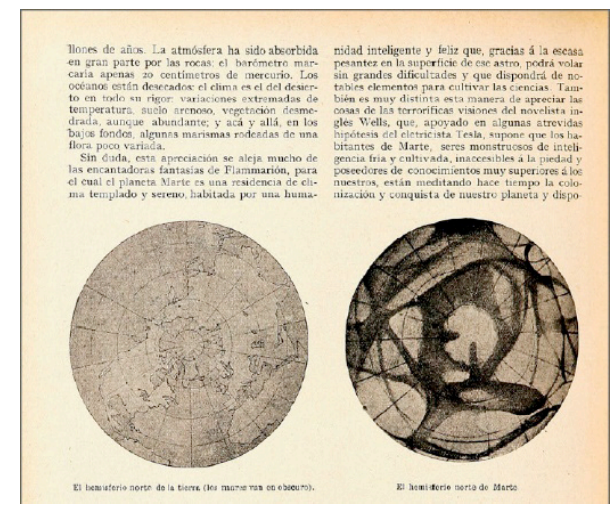

Imagen 3 
Pacífico Magazine, finalmente, publicó en 1913 “De cómo se acabaron los canales de Marte". En el texto se lee:

Un sabio poeta, y más poeta que sabio, Camilo Flammarion, se ha constituido en el último medio siglo, en el apóstol de una astronomía nueva, cuyas conclusiones no se derivan de la tabla de logaritmos, sino de la fantasía más o menos fértil de sus cultivadores. Su éxito ha sido inmenso, y existen hoy en el mundo millones de personas que se imaginan a los astrónomos muy ocupados en averiguar cómo tienen los ojos los habitantes de Júpiter o a los cuántos años son casaderas las niñas bonitas de Neptuno. No es necesario decir que hasta ahora poco han averiguado a este respecto. Lo más probable es que en Neptuno no haya niñas ni bonitas ni feas. (Pacífico Magazine, 1913)

El texto añade que primero fue la Luna el escenario para la fantasía sobre la vida extraterrestre, por lo que luego vendría el turno de Marte, sobre el que: "Con los deleznables elementos de los supuestos mares y continentes, y los misteriosos casquetes polares, los astrónomos poéticos levantaron un mundo y una humanidad" (Pacífico Magazine, 1913). Antes de concluir se entrega una exposición completa de los hitos de la controversia de los canales de Marte, adjuntando reproducciones de las fotografías y dibujos sobre las observaciones que sustentaron la disputa científica. Finalmente, el escrito concluye con lo siguiente: “En el año de 1909 quedaron disipadas todas las dudas. A medida que se observa Marte con mayores telescopios, los canales desaparecen [...]. El edificio de fantasmagorías, levantado sobre la existencia de esas líneas misteriosas, se vino al suelo" (Pacífico Magazine, 1913).

Frenar la imaginación cada cierto tiempo pudo servir para que la revista mantuviese una imagen seria frente a sus lectores. Con esta estrategia creemos que los magazines intentaban conseguir que los públicos más incrédulos volviesen a confiar en ellos. La controversia propiciaba, de este modo, la legitimación de la revista en sí, porque los proyectos quedaban expuestos a la evaluación de su desempeño comunicacional. 
Nuestra intención en este apartado no ha sido acotar los propósitos de los magazines al divertimento y a la información, pues somos conscientes de que estos artefactos comunicacionales desempeñaban otras múltiples funciones, siendo quizás más importante que las anteriores la de "intentar guiar o dar cuerpo a la opinión pública” (Alvarado Cornejo, 2011, 82). Las revistas estudiadas, sin duda, respondían a ciertas tendencias políticas y discursos en general, que influyeron sustancialmente en su manera de presentar el conocimiento científico y, por ende, en los modos en que las audiencias percibieron y se relacionaron con la ciencia. Sin embargo, antes que a una 'ideología' específica, el magazine responde a un negocio, por lo que la venta es su motor estructural y, por ende, se asocia a un periodismo más mesurado e imparcial (Santa Cruz, 2005, 48). En esta seguidilla de intenciones, el conocimiento científico en sí puede pasar a un segundo o tercer plano, siendo muchas veces tratado como un producto moldeable por la oferta del magazine y la demanda del público. Asimismo, en esta cadena de propósitos, la escritura científica es enlazada a otro tipo de escrituras, como la literaria, lo que provoca que el conocimiento científico se desplace y dialogue con distintos discursos y saberes, como hemos podido constatar.

\section{Conclusión}

La teoría sobre la vida extraterrestre basada en la observación de los canales de Marte no solo fue conocida por las comunidades de astrónomos implicados, sino que circuló fuera de la esfera científica y mucho más allá de las fronteras de los principales epicentros de observación astronómica de la época, tales como Estados Unidos, Inglaterra y Francia. La prensa activó la circulación de estos conocimientos científicos hacia zonas periféricas a una velocidad impresionante, como fue el caso de las revistas estudiadas en el contexto chileno que cubrieron la controversia a un ritmo actualizado.

Dentro de los modos en que circuló esta teoría hacia y dentro de Chile, el diálogo del saber científico con la literatura cumplió 
un rol fundamental. Tal como se expuso, pudimos ver la apertura hacia la ficción a partir de datos científicos comprobados, así como la utilización de una realidad virtual para comunicar conocimientos empíricos.

El tratamiento literario de esta controversia astronómica permitió a los magazines captar y mantener la atención de los lectores, procurando atender su demanda de divertimento; lo que a su vez se contrapuso a la necesidad de informar de manera fidedigna, teniendo que debatirse entre una y otra función para conseguir la aprobación de las audiencias y aportar al mantenimiento del negocio editorial.

Lo anterior patentiza la estrecha relación entre el conocimiento científico, la empresa periodística y la literatura en el contexto estudiado, lo que a su vez confirma que la ciencia es un proceso social que necesariamente construye espacios y prácticas de sociabilidad (Sanhueza Cerda, 2018, 15). Esto último, finalmente, fortalece la concepción del desarrollo del conocimiento científico como un proceso comunicativo per se (Secord, 2004, 654), en el que participan diversos agentes y en el que los públicos tienen un rol relevante (Nieto-Galan, 2016, 10).

\section{Referencias bibliográficas}

Alkon, P. (2002) Science Fiction Before 1900. Imagination, Discovers, Technology, Nueva York / Londres, Routledge.

Alvarado Cornejo, M. (2011) “Zig-Zag y la irrupción editorial: La ciudad letrada zigzagueante", Literatura y Lingüística, 23, 81-99.

Asimov, I. (1953) "Social Science Fiction”, en Bretnor, R. (ed.), Modern Science Fiction. Its meaning and its future, Nueva York, Coward-McCann Inc, 157-196.

Correa, M., Kottow, A. y Vetö, S. (eds.) (2016) Ciencia y espectáculo. Circulación de saberes científicos en América Latina, siglos XIX y Xx, Santiago, Ocho Libros.

Crowe, M. (1986) The Extraterrestrial Life Debate 1750-1900. The Idea of a Plurality of Worlds from Kant to Lowell, Cambridge, Cambridge University Press. 
Flammarion, C. (1909) La Planète Mars et ses condition d'habitabilité, Paris, Gauthier Villars Et Fils.

Habermas, J. (1999) Teoría de la acción comunicativa, Madrid, Taurus.

Latour, B. (1987) Science in Action. How to Follow Scientists and Engineers through Society, Cambrigde MA, Harvard University Press.

Marcos, A. (2010) Ciencia y acción. Una filosofía práctica de la ciencia, México, Fondo de Cultura Económica.

Meyer, M. (1980) "Science as a Questioning Process: A Prospect for a New Type of Rationality", Revue Internationale de Philosophie, 131-132, 50-89.

Myers, G. (1990) Writing Biology. Texts in the Social Construction of Scientific Knowledge, Wisconsin, The University of Wisconsin Press.

Nieto-Galan, A. (2010) “La ciencia en la esfera pública del siglo xIx: géneros, discursos y apropiaciones", Cultura Escrita $\mathcal{E}$ Sociedad, 10, 53-80.

Nieto-Galan, A. (2011) Los públicos de la ciencia. Expertos y profanos a través de la historia, Madrid, Marcial Pons.

Nieto-Galan, A. (2016) "Prólogo", en Correa, M., Kottow, A. y Vetö, S. (eds.), Ciencia y espectáculo. Circulación de saberes científicos en América Latina, siglos XIX y xx, Santiago, Ocho Libros, 9-11.

Ossandón, C. y Santa Cruz, E. (2005) El estallido de las formas. Chile en los albores de la cultura de masas, Santiago, LOM.

Quereilhac, S. (2016) Cuando la ciencia despertaba fantasías. Prensa, literatura y ocultismo en la Argentina de entresiglos, Buenos Aires, Siglo XXI.

RenN, J. (2015) "To the History of Science to the History of Knowledge - and Back", Centaurus, 57, 1, 37-53.

Revista Corre-Vuela (1909) "Los habitantes de Júpiter. Un mundo de gigantes y vendaval continuo", 79, s/n.

Revista Corre-Vuela (1911) "Variedades", 196, s/n.

Revista Corre-Vuela (1915) "Paisajes celestes", 384, s/n. 
Revista La Revista de Chile (1898) “Los canales de Marte y de la Luna", 8, 255, s/n.

Revista Pacífico Magazine (1913) “De cómo se acabaron los canales de Marte", 4, 520, s/n.

Revista Sucesos (1907) "Sobre el planeta Marte", 259, s/n.

Revista Sucesos (1908) "Comunicaciones con el planeta Mar$\mathrm{te}^{\prime \prime}, 322, \mathrm{~s} / \mathrm{n}$.

Revista Sucesos (1909) “¿Ha hecho señales Marte?”, 380, s/n.

Revista Sucesos (1914) “¿Vegetación en los planetas?”, 619, s/n.

Revista Zig-Zag (1907) “El llamado de otro mundo", 126, s/n.

Revista Zig-Zag (1908) "Cómo es la vida en Marte", 168, s/n.

Revista Zig-Zag (1915a) “Están habitados los planetas?”, 515 y $516, \mathrm{~s} / \mathrm{n}$.

Revista Zig-Zag (1915b) “El universo ulterior", 530, s/n.

Ruiz-Castell, P. (2011) "Priority claims and public disputes in astronomy: E. M. Antoniadi, J. Comas i Solà and the search for authority and social prestige in the early twenthieth century", BJHS, 44, 509-531.

Sanhueza Cerda, C. (ed.) (2018) La movilidad del saber científico en América Latina: objetos, prácticas e instituciones (siglos XvIII al xx), Santiago, Editorial Universitaria.

Santa Cruz, E. (2005) "El género magazine y sus orígenes", en Ossandón, C., y Santa Cruz, E. (eds.), El estallido de las formas. Chile en los albores de la cultura de masas, Santiago, LOM, 33-59.

Secord, J. (2004) "Knowledge in Transit", Isis, 95, 654-672.

Shapin, S, y Schaffer, S. (1985) Leviathan and the Air-Pump. Hobbes, Boyle, and the Experimental Life, Princeton, Princeton University Press.

Sheenan, W. (1988) Planets and Perception. Telescopie Views and Interpretations 1609-1909, Tucson, The University of Arizona Press.

VAlderrama, L. (2016) “La catástrofe anunciada: terremotos y predicciones en la prensa diaria chilena (1906-1912)", en Correa, M., Kottow, A. y Vetö, S. (eds.), Ciencia y espectáculo. Circula- 
ción de saberes científicos en América Latina, siglos XIx y xx, Santiago, Ocho Libros, 169-175.

White, H. (1973) Metahistoria. La imaginación histórica en la Europa del siglo XIX, México D. F., Fondo de Cultura Económica. 
